Artículo científico

Volumen 32(3):823-840. Septiembre-diciembre, 2021 e-ISSN 2215-3608, doi:10.15517/am.v32i3.44443

https://revistas.ucr.ac.cr/index.php/agromeso/index

\title{
Caracterización fisiológica en plantas de Cannabis medicinal durante distintas etapas fenológicas bajo estrés biótico ${ }^{1}$
}

\section{Physiological characterization in medicinal Cannabis plants during different phenological stages under biotic stress}

\author{
Gustavo Adolfo Rodríguez-Yzquierdo², Manuel Alfonso Patiño-Moscoso², Mónica Betancourt-Vásquez²
}

1 Recepción: 4 de noviembre, 2020. Aceptación: 2 de marzo, 2021.Este trabajo formó parte del proyecto ID 1001057: "Caracterización Materiales Cannabis" desarrollado por la Corporación Colombiana de Investigación Agropecuaria (AGROSAVIA).

2 Corporación Colombiana de Investigación Agropecuaria (AGROSAVIA). Centro de Investigación Tibaitatá. Sede Central. Mosquera, Cundinamarca, Colombia. grodriguezy@agrosavia.co (autor para la correspondencia, https://orcid.org/0000-0003-3709-8534); mpatino@ agrosavia.co (https://orcid.org/0000-0001-6147-032X); mbetancourtv@agrosavia.co (https://orcid.org/0000-0002-6702-9524).

\section{Resumen}

Introducción. Plantas expuestas a condiciones de estrés alteran su funcionamiento y generan respuestas fisiológicas que afectan su desempeño agronómico. En el cultivo de Cannabis medicinal, son escasos los trabajos de investigación sobre la fisiología de la planta y su interacción con factores bióticos. Objetivo. Determinar variables fisiológicas indicadoras de estrés en diferentes etapas fenológicas de plantas de Cannabis en invernadero y bajo condiciones fitosanitarias contrastantes. Materiales y métodos. El estudio se realizó entre noviembre y diciembre de 2019, en el Municipio Rionegro, Antioquia, Colombia. Semanalmente se sembraron lotes de plantas de Cannabis sativa L., provenientes de multiplicación asexual. Entre las semanas seis y doce posteriores al trasplante se evaluaron las variables índice y fluorescencia de clorofila (basal=Fo, máxima=Fm y variable=Fv), diferencial térmico cultivo ambiente, índice de estrés hídrico y concentración foliar de nutrientes desde el inicio de su fase vegetativa hasta la fase reproductiva y productiva, bajo dos condiciones fitosanitarias contrastantes una con la pudrición blanca causada por Sclerotinia sclerotiorum y la otra sin plagas ni patógenos. Resultados. Las plantas no presentaron estrés abiótico que afectara el aparato fotosintético en ninguna etapa. Los valores de cada nutriente estuvieron dentro de los rangos óptimos y los factores edáficos no representaron limitante para el desarrollo del cultivo. Se definieron valores referenciales de variables fisiológicas en distintos estados fenológicos bajo condiciones óptimas de desarrollo. En plantas enfermas con S. sclerotiorum, el índice de clorofila, el índice de estrés hídrico y la fluorescencia, mostraron valores referenciales que pueden ser útiles para la identificación de efectos perjudiciales en el fotosistema II. Conclusiones. En plantas enfermas el índice de clorofila y los parámetros Fv/Fm y Fv/Fo constituyeron variables indicadoras para detectar estrés biótico en plantas de Cannabis. En plantas sanas Fv/Fm, Fv/Fo, CWSI e índice de clorofila pueden evaluarse en experimentos sobre manejo agronómico del cultivo.

Palabras clave: ecofisiología, fluorescencia de clorofila, fotosistema II, Sclerotinia sclerotiorum. 


\begin{abstract}
Introduction. Plants exposed to stress conditions, alter their functioning and generate physiological responses that affect their agronomic performance. In the cultivation of medicinal Cannabis, research on plant physiology and its interaction with biotic factors is scarce. Objective. To determine physiological variables indicative of stress in different phenological stages of Cannabis plants in greenhouse and under contrasting phytosanitary conditions. Materials and methods. The study was carried out between November and December 2019, in the municipality of Rionegro, Antioquia, Colombia. Batches of Cannabis sativa L. plants coming from asexual multiplication were sown weekly. Between weeks six and twelve after transplanting, the chlorophyll index and fluorescence variables (basal=Fo, maximum $=\mathrm{Fm}$ and variable $=\mathrm{Fv}$ ), ambient crop thermal differential, water stress index, and foliar nutrient concentration were evaluated from the beginning of its vegetative phase to the reproductive and productive phase, under two contrasting phytosanitary conditions, one with white rot caused by Sclerotinia sclerotiorum and the other without pests or pathogens. Results. The plants did not present abiotic stress affecting the photosynthetic apparatus at any stage. The values of each nutrient were within the optimal ranges and the edaphic factors did not represent a limitation for the development of the crop. Reference values of physiological variables were defined at different phenological stages under optimal development conditions. In diseased plants with S. sclerotiorum, the chlorophyll index, water stress index, and fluorescence, showed reference values that can be useful for the identification of detrimental effects in the photosystem II. Conclusions. In diseased plants the chlorophyll index and the parameters $\mathrm{Fv} / \mathrm{Fm}$ and $\mathrm{Fv} / \mathrm{F} 0$ constituted indicator variables to detect biotic stress in Cannabis plants. In healthy plants, $\mathrm{Fv} / \mathrm{Fm}$, $\mathrm{Fv} / \mathrm{Fo}, \mathrm{CWSI}$, and chlorophyll index can be evaluated in agronomic crop management experiments.
\end{abstract}

Keywords: ecophysiology, chlorophyll fluorescence, photosystem II, Sclerotinia sclerotiorum.

\title{
Introducción
}

El Cannabis (Cannabis sativa L.) es una importante especie herbácea originaria de Asia Central, que se ha utilizado por más de 5000 años en la medicina popular y como fuente de fibra textil (Booth \& Bohlmann, 2019). Esta planta tiene fitoquímicos y una fuente de fibras celulósicas y leñosas (Andre et al., 2016). Las variedades de Cannabis con bajo contenido de cannabinoides psicoactivos se utilizan para la producción de fibra y productos oleaginosos. Sin embargo, el producto de esta especie más valioso; es la resina, rica en terpenos y cannabinoides, los cuales exhiben diversas propiedades psicoactivas y medicinales (Baron, 2018). La resina se produce y se acumula en tricomas glandulares que cubren, en forma densa, las superficies de las inflorescencias femeninas (pistiladas) y, en menor grado, en el follaje de plantas masculinas y femeninas (Booth \& Bohlmann, 2019).

Esta planta, de rápido crecimiento, ha visto un reciente resurgimiento en su producción comercial, debido a sus aplicaciones multipropósito (Andre et al., 2016). En la actualidad, las leyes sobre el cultivo de Cannabis están cambiando rápidamente en todo el mundo, con la legalización del uso médico que aparece en muchas jurisdicciones, seguida de la legalización del uso recreativo. Por lo tanto, este cultivo con fines medicinales representa una alternativa productiva en Colombia. La producción en este país se encuentra enmarcada en la Ley 1787 de 2016, la cual permite el registro y uso científico o medicinal de materiales ya validados mediante pruebas de evaluación agronómica (PEA).

El sistema productivo comercial de Cannabis en condiciones tropicales, constituye la articulación de diferentes etapas durante la fenología del cultivo. Estas incluyen, inicialmente, el enraizamiento de esquejes, tomados de plantas madre para la propagación de plántulas, durante veintiún días, para luego ser llevados a campo, donde entre 
las semanas 4 y 6 después de trasplante (sdt), atraviesan una etapa vegetativa y a partir de la semana 7 hasta la semana 12 después de establecimiento, alcanzan la etapa reproductiva (Caplan et al., 2019; Potter, 2014).

En la producción agrícola cuando las plantas son expuestas a diferentes condiciones de estrés, como temperaturas extremas, sequía, cambios en la intensidad lumínica, salinidad, deficiencias nutricionales, metales pesados o problemas fitosanitarios, se ve afectado su funcionamiento normal, se generan respuestas particulares y únicas en la fotosíntesis, conductividad estomática, respiración, temperatura foliar y señalización bioquímica (Giraldo et al., 2010). Esto muchas veces se evidencia en el funcionamiento del fotosistema II (PSII), en el contenido de clorofila y en el cierre estomático que conlleva a la disminución de la fijación de $\mathrm{CO}_{2}$, reducción en la eficiencia fotosintética y la transpiración (Sánchez-De-Miguel et al., 2009; Tambussi, 2011; Tarqui-Delgado et al., 2017).

A nivel mundial existen diferentes reportes de enfermedades asociadas al cultivo de Cannabis. Algunos de ellos señalan al Moho gris (Botrytis cinerea) como uno de los patógenos más importantes, el cual bajo condiciones de alta humedad y temperaturas frescas a moderadas, puede alcanzar proporciones epidémicas y destruir por completo un cultivo de Cannabis en una semana (Mcpartland, 2019; Punja et al., 2019), también existen reportes que indican que Sclerotinia sclerotiorum puede causar pérdidas de hasta un $40 \%$ y de Rhizoctonia solani capaz de destruir el $80 \%$ de las plantas. Otros patógenos como los causantes de mildeo polvoso y mildeo velloso, son frecuentes pero rara vez causan problemas serios (Mcpartland, 2019).

Cuando se afecta el funcionamiento del PSII, de manera directa o indirecta, se modifica la emisión de la fluorescencia de clorofila, estos cambios pueden revelar mecanismos de respuesta fisiológica de las plantas. Además puede ser un método para la valoración de la tolerancia de las plantas a condiciones ambientales específicas o inducidas, que permiten cuantificar los efectos del estrés (Delgadillo-Rodríguez et al., 2017).

La fluorescencia de la clorofila es una medida no destructiva, de fácil manejo y rápida respuesta; por medio de las diferentes respuestas de fluorescencia, producidas a partir de la aplicación de destellos de luz, se pueden obtener variados parámetros con los cuales se calcula la eficiencia del PSII. Los parámetros más considerados son: la fluorescencia basal (Fo), emitida cuando los centros de reacción del PSII están abiertos; la fluorescencia máxima (Fm), que ocurre cuando los centros de reacción están cerrados; y la fluorescencia variable (Fv), la cual es la diferencia entre Fo y Fm (Delgadillo-Rodríguez et al., 2017). La relación Fv/Fm es proporcional a la máxima eficiencia fotoquímica primaria de las hojas y es una de las variables de fluorescencia más estudiada por numerosos autores, que han encontrado buenas correlaciones entre este parámetro y diferentes tipos de estrés (Tang et al., 2017).

La temperatura y la humedad relativa juegan un papel importante en el funcionamiento de las plantas de Cannabis, lo que afecta su rendimiento y calidad. La transpiración de la hoja impulsa el crecimiento de la planta, así como la movilización de algunos nutrientes. Por su parte, el déficit de presión de vapor (DPV) es una variable que promueve la transpiración, se refiere a la diferencia entre la presión de vapor dentro de una planta y la presión de vapor del aire que la rodea. Un DPV elevado incrementa la tasa de transpiración de una planta y aumenta la movilización de nutrientes a través del xilema por corriente transpiratoria, mientras que un valor DPV bajo ralentiza el movimiento de nutrientes a través de la planta (Breit et al., 2019).

Uno de los índices más utilizado derivado de esta información térmica es el índice de estrés hídrico del cultivo (CWSI). Este índice, desarrollado por Idso et al. (1981), es una medida de la transpiración que ocurre en una planta en el tiempo de medición, se determina mediante el registro de la temperatura de la planta y el déficit de presión de vapor del agua. Este valor oscila entre 0 a 1 cuando las plantas van de una condición sin estrés hídrico a una condición de estrés (López et al., 2009).

La caracterización fisiológica de Cannabis, es importante, dado el poco conocimiento que se tiene de la fisiología de la planta y su interacción con factores bióticos, en especial para los patógenos que inciden notablemente sobre el desempeño agronómico del cultivo. 
El objetivo de este trabajo fue determinar variables fisiológicas indicadoras de estrés en diferentes etapas fenológicas de plantas de Cannabis en invernadero y bajo condiciones fitosanitarias contrastantes.

\section{Materiales y métodos}

\section{Material vegetal}

La evaluación de variables fisiológicas en Cannabis sativa se realizó en un sistema productivo bajo invernadero comercial con fines medicinales, ubicado en el Municipio Rionegro, departamento de Antioquia, Colombia. Se evaluó un cultivar identificado como CS-0001, clasificado como no psicoactivo $(<1,0 \%$ THC), el cual se propagó en forma clonal, mediante el establecimiento inicial de plantas madre $y$, posterior cosecha de esquejes de propagación vegetativa, inducidas con días largos mediante aplicación de luz artificial.

\section{Periodo experimental}

En plantas con edades entre seis (6) y doce (12) semanas después del trasplante (sdt), se evaluaron distintas variables fisiológicas, durante las siete semanas en los meses de noviembre y diciembre de 2019, desde que la planta inició su fase fenológica vegetativa hasta la fase reproductiva y productiva. Las evaluaciones se realizaron en lotes con frecuencias de siembra semanales, manejados sin condiciones aparentes de estrés. Se identificaron plantas con síntomas de pudrición blanca causada por Sclerotinia sclerotiorum, en las cuales se evaluó su comportamiento fisiológico bajo estrés biótico. Para todas las semanas de evaluación, se tomaron los datos de condiciones ambientales para poder establecer relaciones funcionales con las variables fisiológicas estudiadas.

\section{Manejo del cultivo}

Al material vegetal proveniente de las plantas madre se les realizó una propagación asexual mediante esquejes, cosechados de ramas terminales y con dos pares de hojas, los cuales se desinfectaron y almacenaron a baja temperatura. Luego, se llevaron al área de enraizamiento en bandejas de germinación de 53 celdas, con sustrato a base de turba, perlita y fibra de coco, ya desinfectados.

En el lote plantado se realizó un acondicionamiento previo, que consistió en la aplicación de microorganismos benéficos y adecuación de la estructura del suelo mediante pases de paleadora y nivelación. Una vez que las plántulas cumplieron su fase de vivero y alcanzaron $8 \mathrm{~cm}$ de altura, se procedió al trasplante en campo. Ya establecidas en el lote definitivo, se realizó un control de horas luz, con $18 \mathrm{~h} \mathrm{luz} \mathrm{día}{ }^{-1}$ por catorce días. Luego, las plantas se dejaron el resto de su ciclo con la incidencia de radiación natural bajo las condiciones de invernadero. La densidad de plantación fue 16 plantas por $\mathrm{m}^{2}$.

La dotación hídrica del cultivo se realizó por riego localizado, mediante cintas de goteo de 1,2 $1 \mathrm{~h}^{-1}$ de descarga y separación de goteros de $20 \mathrm{~cm}$. Se realizaron riegos diarios, alternados entre agua pura y agua fertilizada, de acuerdo con el cálculo de la Eto (evapotranspiración de referencia) con base en los datos colectados cada día de la estación climatológica marca WIGA, ubicada en el interior del área experimental. El programa de fertilización de cultivo se efectuó vía fertirriego, tres veces a la semana durante todo el ciclo de cultivo, diferenciado por fases fenológicas.

El manejo de plagas y patógenos se realizó en forma homogénea en todos los lotes evaluados. Se basó en controles biológicos, dado la restricción del uso de moléculas de síntesis en este sistema productivo. Las condiciones ambientales durante el periodo de evaluación se presentan en el Cuadro 1. Las condiciones edáficas y el análisis químico, se presenta en el Cuadro 2. 
Cuadro 1. Condiciones ambientales del área experimental durante el periodo de evaluación de variables fisiológicas de Cannabis sativa cultivar CS-0001. Corporación Colombiana de Investigación Agropecuaria (AGROSAVIA). Antioquia, Colombia. 2020.

Table 1. Environmental conditions of the experimental area during the period of physiological variables evaluation of Cannabis sativa cultivar CS-0001. Corporación Colombiana de Investigación Agropecuaria (AGROSAVIA). Antioquia, Colombia. 2020.

\begin{tabular}{lcccccccc}
\hline Localidad & $\begin{array}{c}\text { Región } \\
\text { Natural }\end{array}$ & $\begin{array}{c}\text { Altura } \\
(\mathbf{m s n m})\end{array}$ & $\begin{array}{c}\text { Temperatu- } \\
\text { ra promedio } \\
\left(\mathbf{C}^{\circ}\right)\end{array}$ & $\begin{array}{c}\text { Temperatu- } \\
\text { ra máxima } \\
\left(\mathbf{C}^{\circ}\right)\end{array}$ & $\begin{array}{c}\text { Temperatu- } \\
\text { ra mínima } \\
\left(\mathbf{C}^{\circ}\right)\end{array}$ & $\begin{array}{c}\text { Humedad } \\
\text { relativa pro- } \\
\text { medio }(\boldsymbol{\%})\end{array}$ & $\begin{array}{c}\text { Humedad re- } \\
\text { lativa máxi- } \\
\text { ma }(\boldsymbol{\%})\end{array}$ & $\begin{array}{c}\text { Humedad } \\
\text { relativa mí- } \\
\text { nima }(\boldsymbol{\%})\end{array}$ \\
\hline $\begin{array}{l}\text { Municipio } \\
\text { Rionegro }\end{array}$ & $\begin{array}{c}\text { Andina, } \\
\text { Cordillera } \\
\text { central }\end{array}$ & 2116 & 23,5 & 24 & 22,8 & 71,4 & 74,1 & 69 \\
\hline
\end{tabular}

Cuadro 2. Características químicas del suelo en el área experimental durante el periodo de evaluación de variables fisiológicas de Cannabis sativa cultivar CS-0001. Corporación Colombiana de Investigación Agropecuaria (AGROSAVIA). Antioquia, Colombia. 2020.

Table 2. Soil chemical characteristics of the experimental area during the period of physiological variables evaluation of Cannabis sativa cultivar CS-0001. Corporación Colombiana de Investigación Agropecuaria (AGROSAVIA). Antioquia, Colombia. 2020.

\begin{tabular}{|c|c|c|}
\hline Determinación analítica & Unidad & Promedio \\
\hline Textura & - & Franco Limoso \\
\hline Nitrógeno total (NT) & g $100 \mathrm{~g}^{-1}$ & 0,68 \\
\hline $\mathrm{pH}(1: 2,5)$ & Unidades de $\mathrm{pH}$ & 6,11 \\
\hline Conductividad eléctrica (CE) (1:5) & $\mathrm{dS} \mathrm{m} \mathrm{m}^{-1}$ & 2,13 \\
\hline Materia orgánica (MO) & g $100 \mathrm{~g}^{-1}$ & 11,04 \\
\hline Fosforo (P) disponible (Bray II) & $\mathrm{mg} \mathrm{kg}^{-1}$ & 187,56 \\
\hline Azufre $(\mathrm{S})$ disponible & $\mathrm{mg} \mathrm{kg}^{-1}$ & 80,88 \\
\hline $\begin{array}{l}\text { Capacidad intercambio catiónico efectivo } \\
\text { (CICE) }\end{array}$ & $\operatorname{cmol}(+) \mathrm{kg}^{-1}$ & 34,89 \\
\hline Boro (B) disponible & $\mathrm{mg} \mathrm{kg}^{-1}$ & 1,67 \\
\hline Acidez $(\mathrm{Al}+\mathrm{H})$ & $\operatorname{cmol}(+) \mathrm{kg}^{-1}$ & No Indica \\
\hline Aluminio $(\mathrm{Al})$ intercambiable & $\operatorname{cmol}(+) \mathrm{kg}^{-1}$ & No indica \\
\hline Calcio $(\mathrm{Ca})$ disponible & $\operatorname{cmol}(+) \mathrm{kg}^{-1}$ & 27,79 \\
\hline Magnesio $(\mathrm{Mg})$ disponible & $\operatorname{cmol}(+) \mathrm{kg}^{-1}$ & 4,85 \\
\hline Potasio (K)disponible & $\operatorname{cmol}(+) \mathrm{kg}^{-1}$ & 1,83 \\
\hline Sodio $(\mathrm{Na})$ disponible & $\operatorname{cmol}(+) \mathrm{kg}^{-1}$ & 0,42 \\
\hline Hierro $(\mathrm{Fe})$ Olsen disponible & $\mathrm{mg} \mathrm{kg}^{-1}$ & 59,59 \\
\hline Cobre $(\mathrm{Cu})$ Olsen disponible & $\mathrm{mg} \mathrm{kg}^{-1}$ & 3,76 \\
\hline Manganeso (Mn) Olsen disponible & $\mathrm{mg} \mathrm{kg}{ }^{-1}$ & 2,35 \\
\hline Zinc (Zn) Olsen disponible & $\mathrm{mg} \mathrm{kg}^{-1}$ & 7,85 \\
\hline Saturación de calcio & $\%$ & 79,48 \\
\hline Saturación de magnesio & $\%$ & 13,81 \\
\hline Saturación de potasio & $\%$ & 5,52 \\
\hline Saturación de sodio & $\%$ & 0,95 \\
\hline Saturación de aluminio & $\%$ & 0,05 \\
\hline
\end{tabular}




\section{Variables fisiológicas}

En veinte plantas por cada lote de edad (plantas entre 6 y 12 sdt) estudiado, en la cuarta hoja sentido ápice base o la hoja recién madura, utilizada como indicadora en el cultivo (Rodríguez-Yzquierdo et al., 2020), se evaluaron las siguientes variables fisiológicas:

- Índice de clorofila: cantidad relativa de clorofila presente en la medición de la absorbancia de la hoja en dos regiones de longitud de onda, se empleó el medidor de clorofila Konica Minolta SPAD-502Plus (unidades SPAD).

- Fluorescencia basal (F0): emitida cuando QA (quinona, receptora primaria de electrones en el PSII) está oxidada y el centro de reacción de PSII está abierto. Relación entre fluorescencia variable y máxima (Fv/Fm) y fluorescencia variable y basal (Fv/F0) (estimación de la eficiencia cuántica máxima de la actividad fotoquímica del PSII cuando todos los centros de reacción del PSII están abiertos). Las determinaciones se realizaron con un fluorómetro marca Opti Sciences OS30p+.

- Diferencial térmico cultivo-ambiente: se utilizó un termómetro infrarrojo con psicrómetro incorporado, marca EXTECH hd500. Se tomaron lecturas de temperatura foliar, ambiental, $\Delta$ temperatura (diferencia entre temperatura foliar y temperatura del aire), punto de rocío (DP) y humedad relativa, de acuerdo con la metodología señalada por Idso (1982).

- Índice de estrés hídrico del cultivo (CWSI): se calculó con los datos obtenidos de temperatura foliar, temperatura ambiental y humedad relativa con base en la ecuación (1) propuesta por López et al. (2009):

$$
C W S I=\frac{(d T-d T i)}{(d T S-d T i)}
$$

Donde $d T=$ diferencia medida entre la temperatura foliar y ambiental; $d T s=$ límite superior de las temperaturas del aire menos la temperatura del follaje (cultivo sin transpiración); $d T i=$ límite inferior de la temperatura del aire menos la temperatura del follaje (cultivo bien regado).

Los valores de $d T s$ y $d T i$ se estimaron según las ecuaciones (2) y (3) propuestas por López et al. (2009):

$$
\begin{gathered}
d T i=a+b(D P V) \\
d T s=a+b[e s(T a)-e s(T a+a)]
\end{gathered}
$$

Donde $D P V=$ déficit de presión de vapor, calculado según la ecuación (4); $a=$ valor del intercepto en la ecuación de regresión lineal entre la diferencia de temperatura foliar y ambiental y el DPV; $b=$ pendiente de la ecuación de regresión lineal entre la diferencia de temperatura foliar y ambiental y el DPV; es $(T a)=$ presión de vapor a saturación a la temperatura del aire $(\mathrm{kPa})$; es $(T a+a)=$ presión de vapor a saturación a la temperatura del aire más el valor del intercepto para el cultivo.

$$
D P V=e s(T a)-0,611 \exp \left[\frac{17,27 * D P}{D P+237,3}\right]
$$

Se tomaron, además, $800 \mathrm{~g}$ de hojas frescas de plantas de cada edad para la determinación del contenido foliar de nitrógeno (método 960.52 Oficial AOAC versión 2016 modificado: Kjeldahl/volumetría), fósforo, 
potasio, calcio, magnesio, azufre, hierro, cobre, manganeso, zinc, sodio (digestión cerrada ácido nítrico: peróxido de hidrógeno (5:2)/ espectrometría de emisión de plasma acoplado de forma inductiva ICP) y boro (calcinación / espectrofotometría VIS).

\section{Identificación molecular del patógeno}

Con el fin de confirmar el agente causal de la pudrición blanca en plantas enfermas, se tomaron secciones de tallo y flor con micelio blanco y esclerocios. Se desinfectaron secuencialmente con hipoclorito de sodio al 2 $\%$ (1 min), agua destilada estéril (1 min), etanol al $70 \%$ (1 min) y agua destilada estéril (1 min) y se sembraron dos trozos por caja en medio PDA (OXOID CMO139) y pH 4,5. Las muestras se incubaron en oscuridad a 25 ${ }^{\circ} \mathrm{C}$ durante siete días. Las colonias puras de cada uno de los aislamientos se caracterizaron a nivel morfológico (macroscópica y microscópica) y a nivel molecular. Se realizó extracción de ADN con base en la metodología propuesta por Griffith \& Shaw (1998) y, luego se realizó amplificación por PCR con los primers ITS1F-ITS4 (ITS1-F 5'-CTTGGTCATTTAGAGGAAGTAA-3' y ITS4 5'-TCCTCCGCTTATTGATATGC-3'). Las secuencias resultantes se compararon con la región ITS1-5.8S- ITS2 correspondiente de las secuencias de la base de datos del GenBank del Centro Nacional para la Información Biotecnológica (NCBI).

\section{Diseño experimental}

Para la evaluación de las variables fisiológicas en las diferentes etapas fenológicas se utilizó un diseño en bloques al azar con siete tratamientos (edades del cultivo) cinco repeticiones y cuatro plantas como unidad experimental.

Para la evaluación de las condiciones sanitarias contrastantes, el diseño fue completamente aleatorizado con dos tratamientos, cinco repeticiones y dos plantas por unidad experimental para la comparación entre plantas sanas y enfermas de once semanas de edad, momento del ciclo del cultivo en donde se obtuvo presencia del patógeno en condiciones de invernadero. Cada una de las plantas seleccionadas se marcaron para realizar todas las evaluaciones.

\section{Análisis estadístico}

Los resultados obtenidos se analizaron con el programa Infostat versión 2017 y Statistix 10. Se revisaron los supuestos del análisis de la varianza y, previa confirmación de estos, se realizaron pruebas paramétricas para aquellas variables que los cumplieron y no paramétricas en caso de incumplimiento de al menos uno de los supuestos. Para el caso de variables cualitativas se siguió la vía no paramétrica para su respectivo análisis. El ANOVA se realizó con base al diseño de bloques al azar con siete o dos tratamientos y seis o cinco repeticiones y un nivel de significancia del $5 \%(\alpha=0,05)$. La prueba de medias utilizada fue Duncan para el ensayo en diferentes etapas fenológicas y una Prueba t para muestras pareadas con el mismo nivel de significancia en el caso de la comparación entre plantas sanas y enfermas.

En las variables no paramétricas se utilizó la prueba de Kruskal-Wallis con determinación de rangos y comparación entre medianas de los tratamientos evaluados. Se calcularon los valores de cuadrados medios de las distintas fuentes de variación y comparación múltiple de medias según el tipo de prueba utilizada. 


\section{Resultados}

\section{Caracterización fisiológica en diferentes edades del cultivo}

Los resultados de las variables asociadas a fluorescencia de clorofila ( $\mathrm{Fv} / \mathrm{Fm}$ y Fv/F0) se presentan en la Figura 1. Los valores manifestaron una tendencia asociada a una función cuadrática, los valores menores se presentaron en la semana 6 y aumentaron hasta la semana 10 y, disminuyeron en las semanas 11 y 12. Igual comportamiento se evidenció en el índice de clorofila, con valores obtenidos entre 44 y 54 unidades SPAD (Figura 2).

1a.

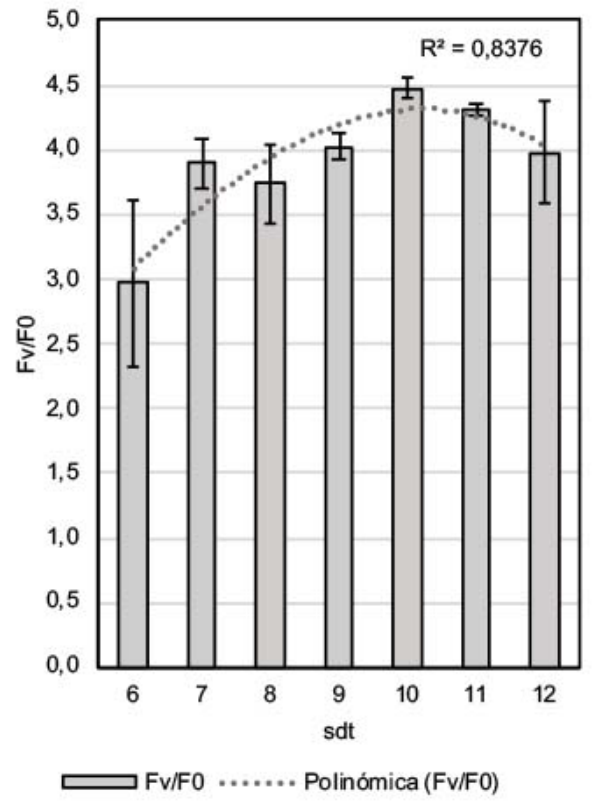

$1 \mathrm{~b}$.

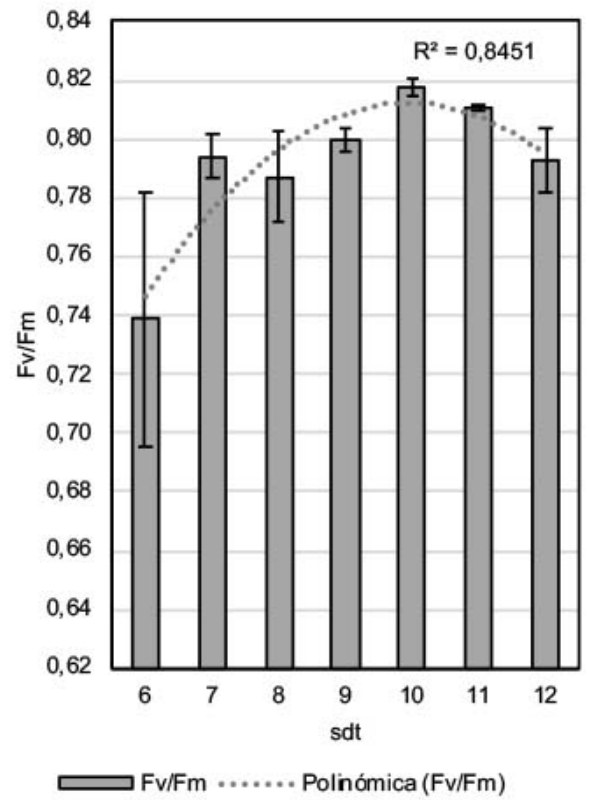

Figura 1. Relaciones de fluorescencia en plantas de Cannabis sativa cultivar CS-001 entre seis y doce semanas después de trasplante (sdt). Corporación Colombiana de Investigación Agropecuaria (AGROSAVIA). Antioquia, Colombia. 2020.

1a. Relación Fv/F0 (izq) 1b. Relación Fv/Fm (der).

Figure 1. Fluorescence relationships in Cannabis sativa cultivar CS-0001 plants between six and twelve weeks after transplantation (sdt). Corporación Colombiana de Investigación Agropecuaria (AGROSAVIA). Antioquia, Colombia. 2020.

1a. Fv / F0 ratio (left). 1b. Fv / Fm ratio (right).

Para el caso del diferencial térmico cultivo-ambiente, el $\Delta$ temperatura en todas las edades fenológicas presentó valores negativos, esto pone en evidencia que, en todos los casos, la temperatura foliar fue más baja que la temperatura del aire, por su parte el comportamiento de los valores de DPV se ajustó a una tendencia polinómica de grado 5 (Figura 3). Estos resultados sugieren que las plantas evaluadas no se encontraban bajo un estrés hídrico que conllevara a un cierre estomático.

En cuanto al índice de estrés hídrico del cultivo (CWSI), los valores en todas las edades evaluadas fueron cercanos a cero, lo cual indica que, para los momentos de evaluación, las plantas de Cannabis no se encontraban bajo estrés hídrico (Cuadro 3). 


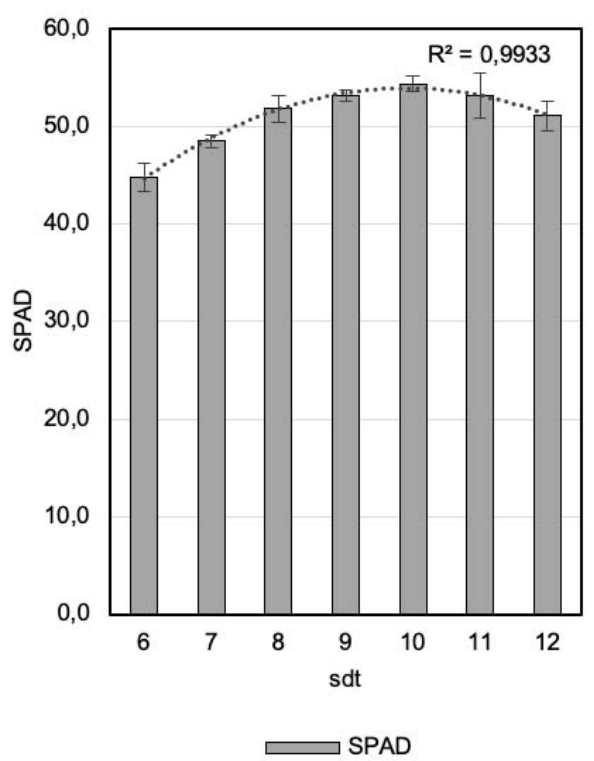

Figura 2. Valores de índice de clorofila (unidades SPAD) en plantas de Cannabis sativa cultivar CS-0001, entre seis y doce semanas después de trasplante (sdt). Corporación Colombiana de Investigación Agropecuaria (AGROSAVIA). Antioquia, Colombia. 2020.

Figure 2. Chlorophyll index values (SPAD units) in Cannabis sativa cultivar CS-0001 plants between six and twelve weeks after transplantation (sdt). Corporación Colombiana de Investigación Agropecuaria (AGROSAVIA). Antioquia, Colombia. 2020.
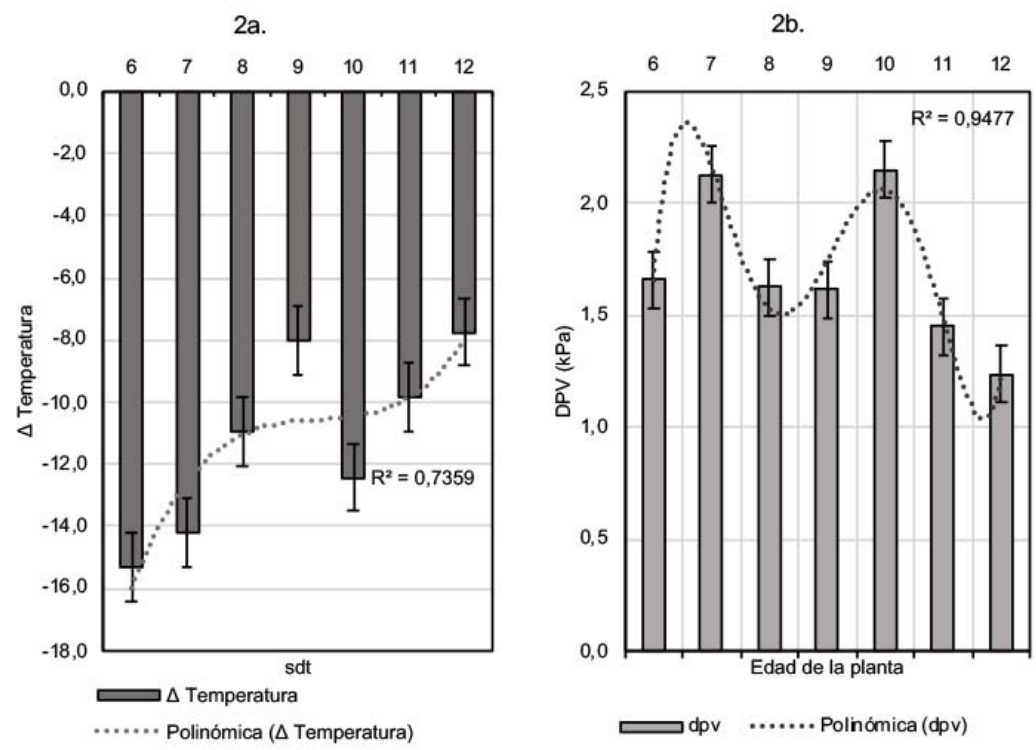

Figura 3. $\Delta$ Temperatura y déficit de presión de vapor (DPV) en plantas de cultivo de Cannabis sativa cultivar CS-0001 entre seis y doce semanas después de trasplante (sdt). 2a. $\Delta$ Temperatura 2b. Déficit de Presión de Vapor (DPV). Corporación Colombiana de Investigación Agropecuaria (AGROSAVIA). Antioquia, Colombia. 2020.

Figure 3. $\Delta$ Temperature and vapor pressure deficit (DPV) in Cannabis sativa cultivar CS-0001cultivation plants between six and twelve weeks after transplantation (sdt). 2a. $\Delta$ Temperature 2b. Vapor Pressure Deficit (DPV). Corporación Colombiana de Investigación Agropecuaria (AGROSAVIA). Antioquia, Colombia. 2020. 
Cuadro 3. Índice de estrés hídrico del cultivo (CWSI) en plantas de Cannabis sativa cultivar CS-0001 entre las las seis y doce semanas después de trasplante (sdt). Corporación Colombiana de Investigación Agropecuaria (AGROSAVIA). Antioquia, Colombia. 2020.

Table 3. Crop water stress index (CWSI) in Cannabis sativa cultivar CS-0001 plants between six and twelve weeks after transplantation (sdt). Corporación Colombiana de Investigación Agropecuaria (AGROSAVIA). Antioquia, Colombia. 2020.

\begin{tabular}{cccccccc}
\hline Edad* (sdt) & $\mathbf{6}$ & $\mathbf{7}$ & $\mathbf{8}$ & $\mathbf{9}$ & $\mathbf{1 0}$ & $\mathbf{1 1}$ & $\mathbf{1 2}$ \\
\hline CWSI & $-0,55( \pm 0,43)$ & $-0,03( \pm 0,23)$ & $-0,03( \pm 0,13)$ & $0,32( \pm 0,29)$ & $0,14( \pm 0,12)$ & $-0,25( \pm 0,94)$ & $0,12( \pm 0,52)$ \\
\hline
\end{tabular}

*sdt: semanas después del trasplante / *sdt: weeks after trasplant.

El análisis de tejido foliar para determinar la concentración de nutrientes, se presentan en el Cuadro 4. Los resultados obtenidos indican que el contenido de B, Ca, Mn y Fe aumentó con la edad del cultivo. Las concentraciones foliares de N, P, K, y S fueron menores con la edad de la planta, mientras que los valores de Na, $\mathrm{Zn}, \mathrm{Cu}$ y $\mathrm{Mg}$ en tejido foliar se mantuvieron constantes.

Cuadro 4. Concentración de nutrientes en tejido foliar de plantas de Cannabis sativa cultivar CS-0001 entre las seis y doce semanas después de trasplante (sdt). Corporación Colombiana de Investigación Agropecuaria (AGROSAVIA). Antioquia, Colombia. 2020.

Table. 4. Nutrient concentration in foliar tissue of Cannabis sativa cultivar CS-0001 plants between six and twelve weeks after transplantation (sdt). Corporación Colombiana de Investigación Agropecuaria (AGROSAVIA). Antioquia, Colombia. 2020.

\begin{tabular}{|c|c|c|c|c|c|c|c|}
\hline \multirow{2}{*}{$\begin{array}{l}\text { Determinación } \\
\text { analítica }\end{array}$} & \multicolumn{7}{|c|}{ Edad (sdt)* } \\
\hline & 6 & 7 & 8 & 9 & 10 & 11 & 12 \\
\hline Nitrógeno (N) (\%) & $5,3( \pm 0,12)$ & $5,42( \pm 0,06)$ & $5,19( \pm 0,05)$ & $4,74( \pm 0,12)$ & $4,29( \pm 0,46)$ & $3,64( \pm 0,28)$ & $2,79( \pm 0,03)$ \\
\hline Fósforo (P) (\%) & $0,44( \pm 0,02)$ & $0,53( \pm 0,01)$ & $0,51( \pm 0,04)$ & $0,45( \pm 0,09)$ & $0,46( \pm 0,04)$ & $0,42( \pm 0,01)$ & $0,32( \pm 0,12)$ \\
\hline Potasio (K) (\%) & $2,62( \pm 0,35)$ & $2,27( \pm 0,06)$ & $2,27( \pm 0,32)$ & $2,05( \pm 0,27)$ & $1,72( \pm 0,17)$ & $1,7( \pm 0,24)$ & $1,38( \pm 0,35)$ \\
\hline Calcio (Ca) (\%) & $6,28( \pm 0,38)$ & $6,06( \pm 0,11)$ & $6,49( \pm 0,81)$ & $6,75( \pm 0,37)$ & $7,08( \pm 0,61)$ & $9,05( \pm 1,49)$ & $8,54( \pm 2,12)$ \\
\hline $\begin{array}{l}\text { Magnesio (Mg) } \\
(\%)\end{array}$ & $0,79( \pm 0,04)$ & $0,75( \pm 0,03)$ & $0,71( \pm 0,04)$ & $0,72( \pm 0,08)$ & $0,76( \pm 0,08)$ & $0,79( \pm 0,02)$ & $0,73( \pm 0,07)$ \\
\hline Azufre (S) (\%) & $0,49( \pm 0,02)$ & $0,45( \pm 0,01)$ & $0,4( \pm 0,03)$ & $0,41( \pm 0,03)$ & $0,44( \pm 0,04)$ & $0,39( \pm 0,02)$ & $0,33( \pm 0,07)$ \\
\hline $\begin{array}{l}\text { Hierro (Fe) (mg } \\
\left.\mathbf{k g}^{-1}\right)\end{array}$ & $\begin{array}{l}159,76 \\
( \pm 1,87)\end{array}$ & $182,39( \pm 11,69)$ & $\begin{array}{c}227,44 \\
( \pm 32,14)\end{array}$ & $\begin{array}{c}200,61 \\
( \pm 24,00)\end{array}$ & $262,45( \pm 34,23)$ & $287,51( \pm 49,85)$ & $270,24( \pm 14,82)$ \\
\hline $\begin{array}{l}\text { Cobre (Cu) (mg } \\
\left.\text { kg }^{-1}\right)\end{array}$ & $28,67( \pm 2,05)$ & $30,25( \pm 4,57)$ & $31,23( \pm 3,9)$ & $11,48( \pm 0,73)$ & $24,69( \pm 1,83)$ & $27,22( \pm 5,77)$ & $13,07( \pm 12,84)$ \\
\hline $\begin{array}{l}\text { Manganeso (Mn) } \\
\left(\mathrm{mg} \mathrm{kg}^{-1}\right)\end{array}$ & $45,63( \pm 5,09)$ & $57,6( \pm 5,58)$ & $\begin{array}{c}69,21 \\
( \pm 12,63)\end{array}$ & $71,18( \pm 16,47)$ & $76,26( \pm 21,23)$ & $83,78( \pm 8,42)$ & $105,53( \pm 24,75)$ \\
\hline $\begin{array}{l}\text { Zinc }(\mathrm{Zn})(\mathbf{m g} \\
\left.\mathbf{k g}^{-1}\right)\end{array}$ & $32,62( \pm 2,05)$ & $45,55( \pm 4,54)$ & $49,39( \pm 3,07)$ & $47,51( \pm 1,98)$ & $54,09( \pm 10,07)$ & $53,68( \pm 9,71)$ & $42,3( \pm 11,26)$ \\
\hline Boro (B) $\left(\mathrm{mg} \mathrm{kg}^{-1}\right)$ & $73,59( \pm 3,89)$ & $75,41( \pm 1,53)$ & $89,06( \pm 6,46)$ & $97,2( \pm 3,12)$ & $114,9( \pm 15,26)$ & $129,77( \pm 2,88)$ & $135,85( \pm 2,45)$ \\
\hline Sodio (Na) (\%) & $\begin{array}{c}0,0064 \\
( \pm 0,0005) \\
\end{array}$ & $\begin{array}{c}0,0072 \\
( \pm 0,0002) \\
\end{array}$ & $\begin{array}{c}0,0073 \\
( \pm 0,0003) \\
\end{array}$ & $\begin{array}{c}0,0067 \\
( \pm 0,0014) \\
\end{array}$ & $\begin{array}{c}0,0062 \\
( \pm 0,0002) \\
\end{array}$ & $\begin{array}{c}0,0105 \\
( \pm 0,0013) \\
\end{array}$ & $\begin{array}{c}0,0068 \\
( \pm 0,0005) \\
\end{array}$ \\
\hline
\end{tabular}

*sdt: semanas después del trasplante / *sdt: weeks after trasplant.

\section{Evaluación de variables fisiológicas en condiciones sanitarias contrastantes}

Para el ensayo bajo condiciones de estrés biótico, las variables fisiológicas, se evaluaron en plantas de once semanas de edad, en condiciones de plantas sanas y enfermas (pudrición blanca causada por S. sclerotiorum) 
(Figura 4). Se presentaron diferencias significativas en las variables índice de clorofila, temperatura foliar, FV/Fm, F/0 y CWSI entre plantas sanas y enfermas (Cuadro 5).

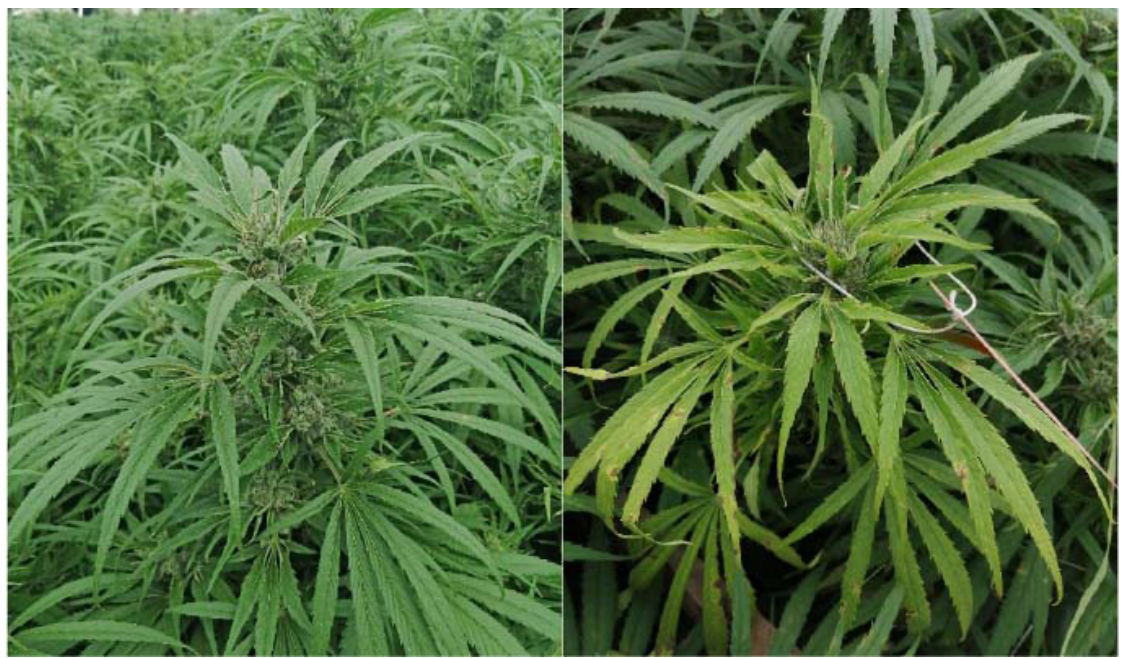

Figura 4. Plantas de Cannabis sativa cultivar CS-0001 de once semanas de edad. Corporación Colombiana de Investigación Agropecuaria (AGROSAVIA), Antioquia, Colombia. 2020.

Izquierda: planta sana, Derecha: planta enferma por pudrición blanca causada por Sclerotinia sclerotiorum.

Figure 4. Eleven-week-old Cannabis sativa cultivar CS-0001 plants. Corporación Colombiana de Investigación Agropecuaria (AGROSAVIA). Antioquia, Colombia. 2020.

Left: healthy plant, Right: diseased plant due to white rot caused by Sclerotinia sclerotiorum.

Cuadro 5. Variables fisiológicas en plantas de Cannabis sativa cultivar CS-0001 sanas y enfermas (pudrición blanca causada por Sclerotinia sclerotiorum) de once semanas de edad. Corporación Colombiana de Investigación Agropecuaria (AGROSAVIA), Antioquia, Colombia. 2020.

Table 5. Physiological variables in healthy and diseased Cannabis sativa cultivar CS-0001 plants (white rot caused by Sclerotinia sclerotiorum) at eleven weeks of age. Corporación Colombiana de Investigación Agropecuaria (AGROSAVIA). Antioquia, Colombia. 2020.

\begin{tabular}{lccccccc}
\hline Variable & SPAD & $\begin{array}{c}\text { Temperatura } \\
\text { foliar }\left({ }^{\circ} \mathbf{C}\right)\end{array}$ & $\begin{array}{c}\Delta \text { Temperatura } \\
\left({ }^{\circ} \mathbf{C}\right)\end{array}$ & DPV $(\mathbf{k P a})$ & Fv/Fm & Fv/F0 & CWSI \\
\hline Plantas sanas & $53,1( \pm 2,6)^{\mathrm{a}}$ & $18,1( \pm 0,7)^{\mathrm{b}}$ & $-9,8( \pm 1,3)^{\mathrm{a}}$ & $1,46( \pm 0,26)^{\mathrm{a}}$ & $0,8( \pm 0,00)^{\mathrm{a}}$ & $4,3( \pm 0,04)^{\mathrm{a}}$ & $-0,25( \pm 0,95)^{\mathrm{b}}$ \\
Plantas enfermas & $29,4( \pm 4,1)^{\mathrm{b}}$ & $19,6( \pm 1,3)^{\mathrm{a}}$ & $-8,9( \pm 1,6)^{\mathrm{a}}$ & $1,61( \pm 0,15)^{\mathrm{a}}$ & $0,6( \pm 0,05)^{\mathrm{b}}$ & $2,8( \pm 0,28)^{\mathrm{b}}$ & $0,25( \pm 0,21)^{\mathrm{a}}$ \\
$\mathbf{C V}(\%)$ & $26,2 \%$ & $8,0 \%$ & $-23,0 \%$ & $10,3 \%$ & $12,0 \%$ & $22,0 \%$ & - \\
\hline
\end{tabular}

DPV: déficit de presión de vapor; Fv/Fm: relación entre fluorescencia variable y máxima; Fv/F0: relación entre fluorescencia variable y basal. Letras diferentes entre columnas se corresponden con diferencias significativas $(\mathrm{p}<0,05)$ de acuerdo con la prueba de $t$ con $\alpha=0,05$ / DPV: vapor pressure deficit; Fv/Fm: ratio between variable and maximum fluorescence; Fv/F0: relationship between variable and baseline fluorescence. Different letters between columns correspond to significant differences $(\mathrm{p}<0.05)$ according to the $t$ test with $\alpha=0.05$.

Se evidenciaron correlaciones positivas entre las variables de SPAD y las relaciones de fluorescencia de clorofila (Figura 4) cuando se incluyeron los valores de plantas enfermas, esto indica que las variables fisiológicas se vieron afectadas cuando las plantas presentaron incidencia de estrés biótico causado por el patógeno $S$. sclerotiorum. 

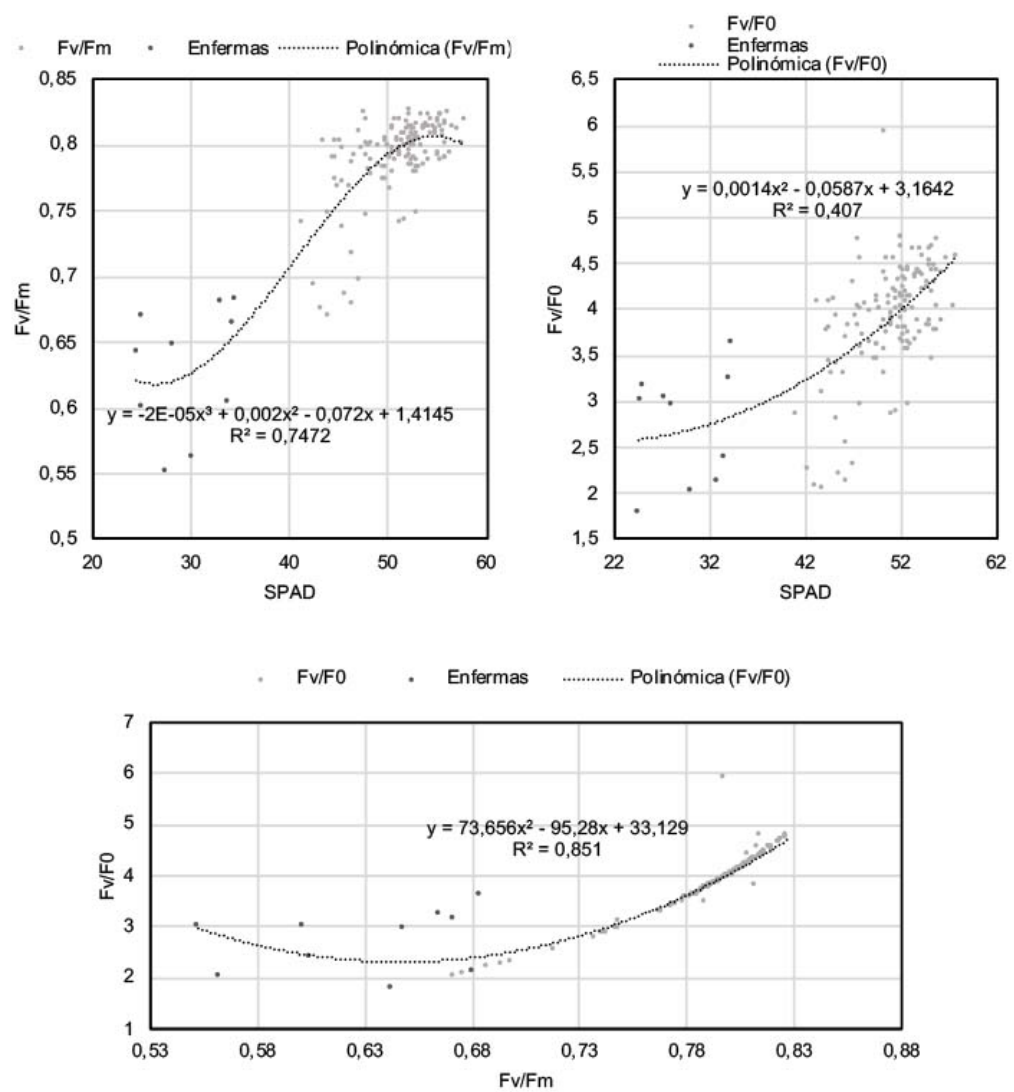

Figura 5. Correlaciones entre relaciones de fluorescencia (Fv/Fm y Fv/F0) y valores SPAD en plantas de Cannabis sativa cultivar CS0001 con condiciones sanitarias contrastantes. Corporación Colombiana de Investigación Agropecuaria (AGROSAVIA), Antioquia, Colombia. 2020.

Fv/Fm: relación entre fluorescencia variable y máxima; Fv/F0: relación entre fluorescencia variable y basal SPAD: índice de clorofila.

Figure 5. Correlations between fluorescence relationships (Fv/Fm and Fv/F0) and SPAD values in Cannabis sativa cultivar CS-0001 plants with contrasting sanitary conditions. Corporación Colombiana de Investigación Agropecuaria (AGROSAVIA). Antioquia, Colombia. 2020.

Fv/Fm: ratio between variable and maximum fluorescence; Fv/F0: relationship between variable and baseline fluorescence; SPAD: chlorophyll index.

De igual modo, se correlacionaron las variables asociadas al diferencial térmico cultivo ambiente (temperatura foliar, temperatura del aire) y el déficit de presión de vapor (Figura 5). Las variables asociadas a la temperatura de la hoja y el aire circundante, junto con el déficit de presión de vapor, no obtuvieron una elevada correlación. Sin embargo, hay una correlación positiva entre la temperatura ambiental y el DPV $\left(R^{2}=0,711\right)$; en este caso, a una mayor temperatura la cantidad de vapor de agua requerida para saturar el ambiente es mayor y, por tanto, la transpiración aumenta. Las correlaciones entre DPV vs temperatura foliar y temperatura ambiental vs temperatura foliar, aunque fueron positivas presentaron un $\mathrm{R}^{2}$ muy bajo cercano a 0,1 (Figura 6). 

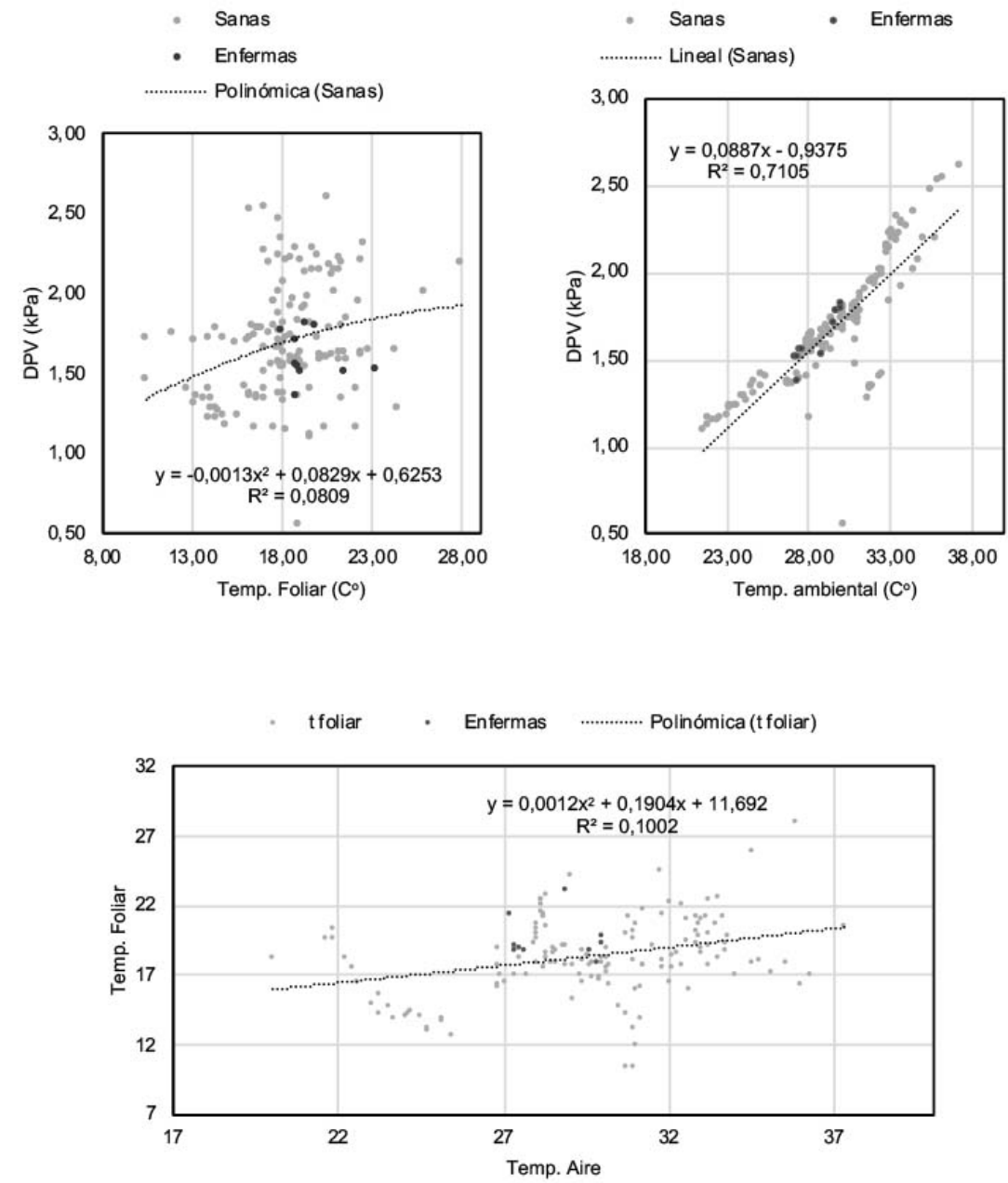

Figura 6. Correlaciones entre temperatura foliar, temperatura del aire y déficit de presión de vapor (DPV) tomadas en plantas de Cannabis sativa cultivar CS-0001 con condiciones sanitarias contrastantes. Corporación Colombiana de Investigación Agropecuaria (AGROSAVIA), Antioquia, Colombia. 2020.

Figure 6. Correlations between leaf temperature, air temperatura, and vapor pressure deficit (VPD) taken in Cannabis sativa cultivar CS-0001 plants with contrasting sanitary conditions. Corporación Colombiana de Investigación Agropecuaria (AGROSAVIA). Antioquia, Colombia. 2020.

\section{Discusión}

Los valores encontrados para la variable Fv/Fm difirieron entre 0,74 y 0,82 , esto coincide con los valores obtenidos, alrededor de 0,8 por Tang et al. (2015) en plantas de Cannabis de treinta días sin ningún tipo de estrés.

Para la variable $\mathrm{Fv} / \mathrm{Fo}$ los valores obtenidos estuvieron en un rango de 2,9 a 4,5. Estos valores son señalados como normales e indican que la relación Fv/F0 contiene la misma información básica que Fv/Fm, pero es mucho más sensible. En tal sentido, esta variable no solo contiene la información básica, sino que presenta valores más altos y un mayor rango dinámico en comparación con Fv/Fm (Jiménez-Suancha et al., 2015). 
Con relación al índice de clorofila los resultados encontrados en la presente investigación variaron entre 45 y 55 unidades SPAD. Para el cultivo de Cannabis, se han reportado valores referenciales de unidades Spad entre 40 y 60 con contenidos óptimos de nitrógeno (Tang et al., 2017). Esto indica que los valores obtenidos encontrados en la presente investigación estuvieron acordes con los valores óptimos reportados y, por ende, no presentaron algún tipo de estrés que indique afectación de procesos asociados a la fotosíntesis y producción de clorofila. El índice de clorofila se encuentra relacionado con el contenido de nitrógeno y magnesio. Esto también se corroboró con los resultados de la parte nutricional, donde los valores de cada nutriente estuvieron dentro de los rangos óptimos señalados por Cockson et al. (2019) en plantas Cannabis de nueve semanas bajo un régimen de fertilización completa, con valores de 4,28 \% (N), 0,43\% (P), 2,85\% (K), 3,73\% (Ca), 0,61\% (Mg) y 0,41\% (S). Asimismo, las concentraciones obtenidas se encuentran dentro de los rangos de suficiencia de N (3,3-4,76 \%), P (0,24-0,49 $\%), \mathrm{K}(1,83-2,35 \%), \mathrm{Mg}(0,40-0,81 \%), \mathrm{Mn}(41-93 \%)$ y Zn (24-52 \%) sugeridos por Bryson \& Mills (2014) para plantas de Cannabis en etapas previas a floración. Sin embargo, fueron superiores a los rangos reportados en elementos como $\mathrm{S}(0,17-0,26)$. Esto último se debe a la aplicación de fungicidas como sulfato de cobre, los cuales son permitidos en el manejo sanitario de Cannabis con fines medicinales y han demostrado incrementar la acumulación de estos compuestos en tejido foliar en varios cultivos (Arru et al., 2004; Lafmejani et al., 2018). De igual modo, los factores edáficos no representaron una limitante para el desarrollo del cultivo.

Los valores negativos obtenidos en la variable diferencial térmico cultivo ambiente indicaron que no se presentaron condiciones de estrés hídrico en el momento en que se realizaron las evaluaciones en las diferentes edades del cultivo. Durante las semanas once y doce la diferencia entre temperaturas foliar y ambiental fue menor; esto podría explicarse por la reducción de la lámina de riego que se aplicó durante esta etapa fenológica como parte del manejo agronómico del cultivo, previo a la cosecha, lo cual se evidenció en la disminución del déficit de presión de vapor (DPV). Este valor basado en la humedad relativa indica la cantidad de vapor de agua necesario para saturar el ambiente. Cuando los valores de DPV son mayores, significa que la cantidad de vapor de agua para saturar el ambiente es mayor y, por tanto, también la transpiración. Los resultados obtenidos en las últimas dos semanas de evaluación, sugieren que cuando hubo una disminución de la lámina de riego, fue probable que la traspiración de la planta fuera menor, pero sin llegar a un nivel de estrés fisiológico (Fletcher et al., 2007).

Los mayores valores de DPV se obtuvieron durante las semanas séptima y décima, esto podría indicar que estos son estadios fenológicos de una elevada actividad metabólica que demandan una mayor captura de carbono para llevar a cabo procesos de fotosíntesis, que les permitan una mayor producción de biomasa (Potter, 2014). La semana décima fue la que presentó los mayores valores de Fv/Fm, Fv/F0, SPAD y $\Delta$ Temperatura (mayor diferencia), por lo que podría considerarse como una posible fase crítica dentro de la etapa reproductiva del cultivo, en la cual evaluar aspectos fisiológicos y nutricionales sea el momento adecuado para su estudio o monitoreo.

En el presente estudio solo las plantas de nueve semanas presentaron un estrés hídrico leve, lo cual se correlaciona con valores de $\Delta$ Temperatura y déficit de presión de vapor (DPV) más bajos con respecto al resto de las edades del cultivo. Se presentaron valores negativos para las determinaciones a las seis, siete, ocho y doce semanas después de trasplante. Si bien se ha indicado que los valores de CSWI varían entre 0 y 1 (López et al., 2009), hay quienes han reportado valores negativos de este índice cuando las plantas se encuentran en un estado hídrico óptimo (De-Jonge et al., 2015; Gonzalez-Dugo et al., 2015; Kacira et al., 2002). Para el índice de estrés hídrico del cultivo, De-Jonge et al. (2015) establecieron valores de CWSI $>0,1$ como indicadores de estrés hídrico leve, CSWI $>0,5$ de estrés moderado y CWSI $\sim 1,0$ de estrés hídrico severo. Con estos resultados se demuestra que las plantas no se encontraron en condiciones de estrés hídrico para los momentos de evaluación, con lo cual las variables fisiológicas evaluadas se corresponden a plantas con buen estatus hídrico.

En el presente estudio los valores de $\Delta$ temperatura fueron cercanos a los $-16^{\circ} \mathrm{C}$ como se muestra en la Figura 2 , lo que corrobora que las plantas para los momentos de evaluación no presentaron estrés hídrico. Se afirmó que cuando la temperatura de la hoja se encuentra entre $1-4{ }^{\circ} \mathrm{C}$ por debajo de la temperatura ambiental, el índice de estrés hídrico del cultivo (CWSI) es 0 (López et al., 2009). 
El índice de clorofila (unidades SPAD) y las variables de fluorescencia fueron significativamente mayores en plantas sanas. Esto indica que el estrés generado por el ataque del patógeno afectó el funcionamiento normal del aparato fotosintético, debido, probablemente, a una disrupción de los haces vasculares de la planta, que impide el transporte de nutrientes y agua (Lobo et al., 2001; Vitorino et al., 2020; Yang et al., 2014).

La pudrición blanca por Sclerotinia sclerotiorum causó en las plantas de Cannabis un aumento en la temperatura foliar, sin embargo, el diferencial térmico cultivo-ambiente presentó valores negativos, esto indicó que la temperatura de la hoja fue menor a la del aire. Este comportamiento se debe a una reducción en la transpiración de la planta causada por un cierre parcial estomático producto de cierto estrés hídrico generado por el daño en los haces vasculares de la planta. S. sclerotiorum inhibe el cierre de estomas en la oscuridad a través de un mecanismo dependiente del ácido oxálico en plantas de haba (Vicia faba) (Guimarães \& Stotz, 2004). Esto tendría relación con los valores de CWSI obtenidos en plantas enfermas (CWSI $=0,25$ ), los cuales son indicadores de un estrés leve (CWSI >0,1) (De-Jonge et al., 2015).

En las correlaciones realizadas para el índice de clorofila y las variables de fluorescencia de clorofila, los valores se ubicaron en la parte inferior de la función. Estos resultados concuerdan con lo reportado por Percival et al. (2008), quienes afirmaron que el contenido de clorofila de la hoja a menudo se correlaciona con las tasas fotosintéticas de la hoja y se reportan correlaciones positivas entre valores SPAD y Fv/Fm en Fagus sylvatica $\left(\mathrm{R}^{2}=0,969\right)$ y Quercus robur $\left(\mathrm{R}^{2}=0\right.$,9413). Autores han manifestado que un modelo matemático exponencial se ajustó mejor a la relación entre las lecturas SPAD y la relación Fv/Fm $\left(\mathrm{R}^{2}=0,712\right)$ en Oryza sativa L (Kumagai et al., 2009).

Las plantas enfermas presentaron valores de índice de clorofila bajo ( $<30$ unidades SPAD), lo cual es un indicativo de afectación del aparato fotosintético relacionado por los efectos del patógeno, en este caso un estrés biótico (Basso et al., 2019). En plantas de maracuyá sometidas a estrés por inundación se obtuvieron valores de índice de clorofila menores a 30 unidades SPAD (Basso et al., 2019); en el mismo cultivo, Rodriguez-Yzquierdo et al. (2020) obtuvieron valores en plantas sin estrés de entre 40 y 50 unidades SPAD. Estas variables podrían ser útiles para la detección de plantas enfermas o sometidas a algún tipo de estrés en campo. Por su parte, la reducción de un $25 \%$ de los valores de Fv/Fm de plantas enfermas en comparación con plantas sanas, demostraron la afectación del fotosistema II en los tratamientos con incidencia de Sclerotinia sclerotium.

La variable Fv/F0 presentó una disminución en un $35 \%$ en plantas enfermas en comparación a plantas sanas, demostrado también por ser una variable sensible al estrés causado por $S$. sclerotiorum. Este agotamiento fotosintético es inducido por una reducción significativa en la producción cuántica máxima del fotosistema (PS) II (Fv/Fm) (Vitorino et al., 2020; Yang et al., 2014). En la comparación de plantas sanas y enfermas, se observó de nuevo que al aumentar el contenido de índice de clorofila, las relaciones de fluorescencia eran igualmente mayores.

A diferencia de las correlaciones de fluorescencia y SPAD, las variables asociadas a la temperatura de la hoja y el aire circundante, junto con el déficit de presión de vapor, no obtuvieron una elevada correlación. Sin embargo, hubo una alta correlación positiva entre la temperatura ambiental y el DPV $\left(\mathrm{R}^{2}=0,711\right)$; en este caso, a una mayor temperatura la cantidad de vapor de agua requerida para saturar el ambiente fue mayor y, por tanto, la transpiración aumentó. Las correlaciones entre DPV vs temperatura foliar y temperatura ambiental vs temperatura foliar, aunque fueron positivas presentaron un $\mathrm{R}^{2}$ muy bajo cercano a 0,1 . Incluso, se habría esperado que a mayor DPV, la temperatura de la hoja fue menor por una mayor transpiración, en este caso la distribución de los datos fue casi aleatoria. El posible mecanismo subyacente es que la alta temperatura puede disminuir la viscosidad del agua y aumentar la permeabilidad de la membrana de la planta y, por ende, aumentar el suministro de agua para proteger las células, lo cual resulta en una mayor conductancia estomática. La conductancia del estoma de la hoja podría aumentar a medida que aumenta el DPV cuando este es bajo, pero disminuye con el aumento de DPV cuando es alto (Li et al., 2018).

Los resultados encontrados en las variables índice de clorofila, CWSI, Fv/Fm y Fv/F0 en plantas enfermas con incidencia de Sclerotinia sclerotium, representan valores referenciales en plantas sometidas por estrés biótico que pueden ser útiles para la identificación de efectos en el fotosistema II que inciden sobre el comportamiento 
fisiológico de la planta y que pueden ser tenidos en cuenta para el cultivo de Cannabis en procesos de investigación relacionados con estudios de ecosifiología bajo diferentes ambientes. De igual modo, en plantas sin estrés se obtuvieron valores en estas variables que podrían ser considerados como criterios de referencia frente a evaluaciones relacionadas con el manejo agronómico del cultivo para factores como nutrición y riego.

\section{Conclusiones}

El índice de clorofila y los parámetros de fluorescencia de clorofila Fv/Fm y Fv/Fo constituyeron variables indicadoras para detectar estrés biótico en plantas de Cannabis, bajo la incidencia de la pudrición blanca causada por Sclerotinia sclerotiorum y sin plagas ni patógenos.

En plantas sanas, las variables Fv/Fm, Fv/Fo, CWSI e índice de clorofila, presentaron valores referenciales que pueden ser monitoreados y tenidos en cuenta para experimentaciones enmarcadas dentro del manejo del cultivo durante las fases fenológicas de la planta.

\section{Agradecimientos}

Los autores agradecen a la Corporación Colombiana de Investigación Agropecuaria (AGROSAVIA), por los recursos asociados al proyecto ID 1001057: Caracterización materiales Cannabis.

\section{Referencias}

Andre, C. M., Hausman, J. F., \& Guerriero, G. (2016). Cannabis sativa: The plant of the thousand and one molecules. Frontiers in Plant Science, 7, Article 19. https://doi.org/10.3389/fpls.2016.00019

Arru, L., Rognoni, S., Baroncini, M., Bonatti, P. M., \& Perata, P. (2004). Copper localization in Cannabis sativa L. grown in a copper-rich solution. Euphytica, 140(1-2), 33-38. https://doi.org/10.1007/s10681-004-4752-0

Baron, E. P. (2018). Medicinal properties of cannabinoids, terpenes, and flavonoids in cannabis, and benefits in migraine, headache, and pain: An update on current evidence and cannabis science. Headache, 58(7), 1139-1186. https://doi. org/10.1111/head.13345

Basso, C., Rodríguez, G., Rivero, G., León, R., Barrios, M., \& Díaz, G. (2019). Respuesta del cultivo de maracuyá (Passiflora edulis Sims) a condiciones de estrés por inundación. Bioagro, 31(3), 185-192.

Booth, J. K., \& Bohlmann, J. (2019). Terpenes in Cannabis sativa - From plant genome to humans. Plant Science, $284,67-72$. https://doi.org/10.1016/j.plantsci.2019.03.022

Breit, L., Leavitt, M., \& Boyd, A. (2019). Understanding VPD and transpiration rates for cannabis cultivation operations. Cannabis Science and Technology, 2(2), 52-61.

Bryson, G., \& Mills, H. A. (2014). Plant analysis handbook IV eedition. A guide to sampling, preparation, analysis, and interpretation for agronomic and horticultural crops. Micro-Macro Publishing.

Caplan, D., Dixon, M., \& Zheng, Y. (2019). Increasing inflorescence dry weight and cannabinoid content in medical cannabis using controlled drought stress. HortScience, 54(5), 964-969. https://doi.org/10.21273/HORTSCI13510-18 
Cockson, P., Landis, H., Smith, T., Hicks, K., \& Whipker, B. E. (2019). Characterization of nutrient disorders of Cannabis sativa. Applied Sciences, 9(20), Article 4432. https://doi.org/10.3390/app9204432

De-Jonge, K. C., Taghvaeian, S., Trout, T. J., \& Comas, L. H. (2015). Comparison of canopy temperature-based water stress indices for maize. Agricultural Water Management, 156, 51-62. https://doi.org/10.1016/j.agwat.2015.03.023

Delgadillo-Rodríguez, I. P., Montenegro Ruíz, L. C., Pinilla Agudelo, G. A., \& Melgarejo, L. M. (2017). Measuring of the chlorophyll a fluorescence in calcium alginate-encapsulated algae. Acta Biológica Colombiana, 22(2), $199-208$. https://doi.org/10.15446/abc.v22n2.56166

Fletcher, A. L., Sinclair, T. R., \& Allen, L. H. (2007). Transpiration responses to vapor pressure deficit in well watered "slowwilting" and commercial soybean. Environmental and Experimental Botany, 61(2), 145-151. https://doi.org/10.1016/j. envexpbot.2007.05.004

Giraldo, C. J., Cano, M. A. O., \& Ribas, R. F. (2010). Respuesta fotosintética de diferentes ecotipos de fríjol a la radiación y la salinidad. Ciencia y Tecnología Agropecuaria, 10(2), 129-140. https://doi.org/10.21930/rcta.vol10_num2_art:135

Gonzalez-Dugo, V., Goldhamer, D., Zarco-Tejada, P. J., \& Fereres, E. (2015). Improving the precision of irrigation in a pistachio farm using an unmanned airborne thermal system. Irrigation Science, 33, 43-52. https://doi.org/10.1007/s00271-014-0447-z

Griffith, G. W., \& Shaw, D. S. (1998). Polymorphisms in Phytophthora infestans: Four mitochondrial haplotypes are detected after PCR amplification of DNA from pure cultures or from host lesions. Applied and Environmental Microbiology, 64(10), 4007-4014. https://doi.org/10.1128/aem.64.10.4007-4014.1998

Guimarães, R. L., \& Stotz, H. U. (2004). Oxalate production by Sclerotinia sclerotiorum deregulates guard cells during infection. Plant Physiology, 136(3), 3703-3711. https://doi.org/10.1104/pp.104.049650

Idso, S. B. (1982). Non-water-stressed baselines: A key to measuring and interpreting plant water stress. Agricultural Meteorology, 27(1-2), 59-70. https://doi.org/10.1016/0002-1571(82)90020-6

Idso, L. B., Jackson, R. D., Pinter, P. J., Reginato, R. J., \& Hatfield, J. L. (1981). Normalizing the stress-degree-day parameter for environmental variability. Agricultural Meteorology, 24, 45-55. https://doi.org/10.1016/0002-1571(81)90032-7

Jiménez-Suancha, S. C., Álvarado, O. H., \& Balaguera-López, H. E. (2015). Fluorescencia como indicador de estrés en Helianthus annuus L. Una revisión. Revista Colombiana de Ciencias Hortícolas, 9(1), 149-160. https://doi. org/10.17584/rcch.2015v9i1.3753

Kacira, M., Ling, P. P., \& Short, T. H. (2002). Establishing crop water stress index (CWSI) threshold values for early, noncontact detection of plant water stress. Transactions of the American Society of Agricultural Engineers, 45(3), 775-780. https://doi.org/10.13031/2013.8844

Kumagai,E.,Araki, T., \& Kubota, F. (2009). Correlation of chlorophyll meter readings with gas exchange and chlorophyll fluorescence in flag leaves of rice (Oryza sativa L.) plants. Plant Production Science, 12(1), 50-53. https://doi.org/10.1626/pps.12.50

Lafmejani, Z., Jafari, A., Moradi, P., \& Moghadam, A. 2018. Impact of foliar application of copper sulphate and copper nanoparticles on some morpho-physiological traits and essential oil composition of peppermint (Mentha piperita L.). Herba Polonica, 64(2), 13-24. https://doi.org/10.2478/hepo-2018-0006

Li, Y., Zhou, L., Wang, S., Chi, Y., \& Chen, J. (2018). Leaf temperature and Vapour Pressure Deficit (VPD) driving stomatal conductance and biochemical processes of leaf photosynthetic rate in a subtropical evergreen coniferous plantation. Sustainability, 10(11), Article 4063. https://doi.org/10.3390/su10114063 
Lobo, M., Lopes, C. A., \& Silva, W. L. C. (2001). Sclerotinia rot losses in processing tomatoes grown under centre pivot irrigation in central Brazil. Plant Pathology, 49(1), 51-56. https://doi.org/10.1046/j.1365-3059.2000.00394.x

López, R., Arteaga, R., Vázquez, M. a., López, I., \& Sánchez, I. (2009). Índice de estrés hídrico como un indicador del momento de riego en cultivos agrícolas. Agricultura Técnica en México, 35(1), 97-111.

Mcpartland, J. M. (2019). A review of Cannabis diseases. Journal of the International Hemp Association, 3(1), 19-23.

Percival, G. C., Keary, I. P., \& Noviss, K. (2008). The potential of a chlorophyll content SPAD meter to quantify nutrient stress in foliar tissue of sycamore (Acer pseudoplatanus), English oak (Quercus robur), and European beech (Fagus sylvatica). Arboriculture and Urban Forestry, 34(2), 89-100.

Potter, D. J. (2014). A review of the cultivation and processing of cannabis (Cannabis sativa L.) for production of prescription medicines in the UK. Drug Testing and Analysis, 6(1-2), 31-38. https://doi.org/10.1002/dta.1531

Punja, Z. K., Collyer, D., Scott, C., Lung, S., Holmes, J., \& Sutton, D. (2019). Pathogens and molds affecting production and quality of Cannabis sativa L. Frontiers in Plant Science, 10, Article 1120. https://doi.org/10.3389/fpls.2019.01120

Rodriguez-Yzquierdo, G. A., Basso-de-Figuera, C. A., Díaz-Reyes, G., \& León-Pacheco, R. I. (2020). Riego deficitario controlado su efecto sobre la nutrición, productividad y calidad de fruta en maracuyá. Agronomía Mesoamericana, 31(2), 405-418. https://doi.org/10.15517/am.v31i2.39647

Sánchez-De-Miguel, P., Junquera, P., Jiménez, L., \& Lissarrague, J. R. (2009). Efectos de la temperatura foliar y de la humedad relativa en la respuesta fotosintética a la luz de las hojas de vid de los cvs. Cabernet Sauvignon y Tempranillo, en el período de maduración. Revista Enología, 1(6), 1-8.

Tambussi,E.A.(2011).Fotosíntesis, fotoprotección, productividad y estreses abióticos: casos de estudio [Tesis Doctoral, Universidad de Barcelona]. Depósito Digital de la Universidad de Barcelona. http://diposit.ub.edu/dspace/handle/2445/36093

Tang, K., Struik, P. C., Amaducci, S., Stomph, T. J., \& Yin, X. (2017). Hemp (Cannabis sativa L.) leaf photosynthesis in relation to nitrogen content and temperature: implications for hemp as a bio-economically sustainable crop. GCB Bioenergy, 9(10), 1573-1587. https://doi.org/10.1111/gcbb.12451

Tang, Y., Bao, Q., Tian, G., Fu, K., \& Cheng, H. (2015). Heavy metal cadmium tolerance on the growth characteristics of industrial hemp (Cannabis sativa L.) in China. In S. Chen, \& S. Zhou (Eds.), Proceedings of the International Conference on Advances in Energy, Environment and Chemical Engineering (pp. 289-295). Atlantis Press. https:// doi.org/10.2991/aeece-15.2015.58

Tarqui Delgado, M., Mena Herrera, F. C., Quino Luna, J. J., Gutiérrez Villalobos, S., \& Coela Poma, R. R. (2017). Leaflet temperature of lettuce (Lactuca sativa) and air influenced by the vapor pressure deficit. Revista de Investigación e Innovación Agropecuaria y de Recursos Naturales, 4(1), 60-66.

Vitorino, L. C., da Silva, F. O., Cruvinel, B. G., Bessa, L. A., Rosa, M., Souchie, E. L., \& Silva, F. G. (2020). Biocontrol potential of Sclerotinia sclerotiorum and physiological changes in soybean in response to Butia archeri palm Rhizobacteria. Plants, 9, Article 64. https://doi.org/10.3390/plants9010064

Yang, C., Zhang, Z., Gao, H., Liu, M., \& Fan, X. (2014). Mechanisms by which the infection of Sclerotinia sclerotiorum (Lib.) de Bary affects the photosynthetic performance in tobacco leaves. BMC Plant Biology, 14, Article 240. https://doi. org/10.1186/s12870-014-0240-4 